\title{
A Enfermagem no ensino superior: estratégias utilizadas pelo enfermeiro docente para melhoria de suas práticas pedagógicas
}

\author{
Nursing in higher education: strategies used by the teaching nurse to improve their \\ pedagogical practices
}

\section{La Enfermería en la enseñanza superior: estrategias utilizadas por el enfermero docente para mejorar sus prácticas pedagógicas}

Francisco Lucas de Lima Fontes ${ }^{1 *}$, Rosane da Silva Santana ${ }^{2}$, llana Maria do Espírito Santo ${ }^{3}$, Renata Natoeli dos Santos Barros ${ }^{4}$, Míriam Cláudia Fausto de Sousa Maroja ${ }^{5}$, Beatriz Azevedo Pinheiro Nahum ${ }^{5}$, Karine do Nascimento Miranda Martins Granjeiro ${ }^{6}$, Márcia Sandra Rêgo de Sousa ${ }^{3}$, Josélia Costa Soares ${ }^{1}$, Ilana Isla Oliveira1, Janária Oliveira Figueiredo¹, Francisca Jéssica Abreu da Silva¹, Léa Jane Gomes Silva³, Ayla Cristina Rodrigues Ramos da Costa ${ }^{1}$, Marlúcia de Sousa Rodrigues ${ }^{1}$.

\section{RESUMO}

Objetivo: Analisar as estratégias de ensino utilizadas pelo enfermeiro docente para melhoria de suas práticas pedagógicas. Metodologia: Trata-se de um estudo descritivo com abordagem qualitativa, desenvolvido em uma universidade pública federal do município de Teresina-PI. Os sujeitos da pesquisa foram 12 enfermeiros docentes lotados em disciplinas teóricas. Os dados foram coletados por meio de entrevista semiestruturada entre os meses de fevereiro a abril de 2018, após aprovação do Comitê de Ética em Pesquisa. Resultados: Ações como manter-se atualizado, participação em cursos e eventos científicos para aperfeiçoamento e qualificação, leitura rotineira, diagnóstico do feedback dos alunos acerca das aulas e conteúdos ministrados e produção científica foram alguns pontos discutidos com os entrevistados. Conclusão: Revela-se a importância de ações como escuta ativa, eliminação de dúvidas, encorajamento, incentivo ao raciocínio crítico e empatia, pois o professor deve se atentar que, antes de ser educador, ele também já esteve ocupando a mesma carteira que seus alunos se encontram.

Palavras-chave: Prática do Docente de Enfermagem, Docentes de Enfermagem, Ensino Superior.

\section{ABSTRACT}

Objective: To analyze the teaching strategies used by the teaching nurse to improve their pedagogical practices. Methodology: This is a descriptive study with a qualitative approach, developed at a federal public university in the city of Teresina-PI. The subjects of the research were 12 teaching nurses full of theoretical subjects. Data were collected through a semistructured interview between February and April 2018, after authorization from the Research Ethics Committee. Results: Actions such as keeping up to date, participation in scientific courses and events for improvement and qualification, routine reading, diagnosis of students'

\footnotetext{
1 Faculdade UNINASSAU - Campus Redenção. Teresina, Piauí, Brasil. E-mail: lucasfontesenf@hotmail.com

2 Universidade Federal do Ceará. Fortaleza, Ceará, Brasil.

${ }^{3}$ Centro Universitário Uninovafapi. Teresina, Piauí, Brasil.

${ }^{4}$ Faculdade de Tecnologia e Educação Superior Profissional. Teresina, Piauí, Brasil.

5 Faculdade UNINASSAU. Belém, Pará, Brasil.

${ }^{6}$ Universidade do Rio Grande. Rio de Janeiro, Rio de Janeiro, Brasil.
} 
feedback about classes and contents given and scientific production were some points discussed with the interviewees. Conclusion: The importance of actions such as active listening, elimination of doubts, encouragement, encouragement of critical thinking and empathy is revealed, since the teacher must be aware that before he was an educator, he has also been occupying the same portfolio as his students meet.

Keywords: Nursing Faculty Practice, Faculty Nursing, Education Higher.

\section{RESUMEN}

Objetivo: Analizar las estrategias de enseñanza utilizadas por el enfermero docente para mejorar sus prácticas pedagógicas. Metodología: Se trata de un estudio descriptivo con abordaje cualitativo, desarrollado en una universidad pública federal del municipio de Teresina-PI. Los sujetos de la investigación fueron 12 enfermeros docentes abarrotados en disciplinas teóricas. Los datos fueron recolectados por medio de una entrevista semiestructurada entre los meses de febrero a abril de 2018, después de la autorización del Comité de Ética en Investigación. Resultados: Acciones como mantenerse actualizado, participación en cursos y eventos científicos para perfeccionamiento y calificación, lectura rutinaria, diagnóstico de la retroalimentación de los alumnos acerca de las clases y contenidos ministrados y producción científica fueron algunos puntos discutidos con los entrevistados. Conclusión: Se revela la importancia de acciones como escucha activa, eliminación de dudas, aliento, incentivo al raciocinio crítico y empatía, pues el profesor debe observarse que, antes de ser educador, él también ya estuvo ocupando la misma cartera que sus alumnos se encuentran.

Palavras-clave: Práctica del Docente de Enfermería, Docentes de Enfermería, Educación Superior.

\section{INTRODUÇÃO}

A docência do ensino superior exige que, além de conhecimentos singulares da sua área de formação, o docente trabalhe com fundamentos pedagógicos do processo ensino-aprendizagem associados aos saberes de sua vivência profissional e de sua produção científica. Nessa perspectiva, é interessante que o docente não se limite ao campo de atuação para o qual foi formado. É necessário que ele compreenda o processo de ensino-aprendizagem, estruturando a metodologia de ensino e o conhecimento do plano pedagógico institucional da área de atuação (JUNGES e BEHRENS, 2015; SANTOS et al., 2016).

A prática do professor universitário, fundamenta-se em três eixos de competências: área do conhecimento, domínio em campo pedagógico e dimensão política. A área do conhecimento relaciona-se ao domínio de conteúdos essenciais na área de atuação associada à vivência profissional. O domínio do campo pedagógico transpõe o processo de ensino-aprendizagem que engloba o controle afetivo/emocional/espiritual, a cognição, as habilidades e as atitudes, que servirão de suporte para a interdisciplinaridade e interação. É fundamental que o docente tenha ética no exercício profissional e no campo político, sendo um cidadão participativo e comprometido com a sociedade (BARBOSA e AGUIAR, 2016).

O professor, ao analisar sua prática, reflete acerca da rotina acadêmica e dos obstáculos e debilidades associados a ela, ao passo em que vivencia a situação. Tal prática se desenvolve por meio da complexidade dinâmica, propriedade do fazer pedagógico, sendo uma reflexão de suas próprias práticas. Por isso, o docente ao repensar sua prática deve compreender suas ações propositando a criação de planos e opções para mudança de determinadas situações (BOCCIA e SOUZA, 2014).

A Enfermagem por ser uma profissão com diversos campos de atuação sofre constantes transformações, refletindo diretamente na maneira de praticar a profissão. Boa parte dos enfermeiros vêm assumindo o espaço da sala de aula, ambiente usado a princípio para ensino e habilitação profissional. A docência traduz-se como uma possibilidade de atuação contínua nas mais diversas oportunidades que a Enfermagem oferece como profissão. O enfermeiro, cuja formação inicial, volta-se predominantemente para assistência à saúde do 
paciente, tem atuado com maior frequência no ensino de cursos técnico e superior em Enfermagem (FONSECA e FERNANDES, 2017).

A formação dos profissionais da saúde, em especial do enfermeiro, visa uma metodologia dialética no ensino-aprendizagem, pautada no diálogo, na argumentação e na discussão. O enfermeiro adota modelos educativos e passa a utilizar concepções pedagógicas que superem a simples transmissão de conhecimento, criando estratégias para o enfrentamento de situações difíceis e contrastantes da vivência diária no ensino, o que leva a superação de empecilhos e criação de vias alternativas (GATTO JUNIOR et al., 2015).

A construção do enfermeiro docente deve ser fundamentada em conhecimentos científicos e na prática investigativa do ensinar e do aprender, ocasionando uma aprendizagem ativa (MATTOS e MONTEIRO, 2014). A Enfermagem e a Educação são áreas do conhecimento distintas, mas que, quando aliadas visam a construção do saber e o desenvolvimento de pessoas críticas, dinâmicas e hábeis para atuarem nos mais diversos campos que a profissão proporciona. Diante do que foi explanado, o objetivo do presente estudo foi analisar as estratégias de ensino utilizadas pelo enfermeiro docente para melhoria de suas práticas pedagógicas.

\section{METODOLOGIA}

Trata-se de um estudo descritivo com abordagem qualitativa, desenvolvido em uma universidade pública federal do município de Teresina-PI. Os dados foram coletados, especificamente, no Departamento de Enfermagem da instituição, escolhido por ofertar o ensino de Enfermagem há 43 anos. Os sujeitos da pesquisa foram 12 enfermeiros docentes lotados em disciplinas teóricas. A escolha dos participantes foi realizada de forma aleatória até constituir a amostra final. Foram incluídos apenas os docentes enfermeiros, que ministravam disciplinas teóricas com experiência mínima de três anos na instituição; e excluídos, aqueles que se encontravam exclusivamente em atividades práticas. As entrevistas foram encerradas pelo critério de reincidência, ou seja, quando as percepções, explicações, e sentidos atribuídos pelos entrevistados começaram a ter uma regularidade, não definindo novas categorias ou representações (MINAYO, 2014).

Os dados foram coletados por meio de entrevista semiestruturada entre os meses de fevereiro a abril de 2018, após a autorização do Comitê de Ética em Pesquisa da Faculdade de Ciências e Tecnologia do Maranhão (FACEMA) no CAAE 82103318.7.0000.8007 com ํo de parecer 2.492.663. O instrumento para coleta de dados foi constituído por duas etapas: a primeira, com dados pessoais e profissionais para caracterizar o perfil do grupo entrevistado, e a segunda, composta por questionamento aberto sobre o tema, com vistas ao alcance do objetivo da pesquisa.

As entrevistas foram agendadas via telefone e realizadas nas dependências da instituição de ensino, em uma sala privada. Aqueles que aceitaram participar do estudo, assinaram o Termo de Consentimento Livre e Esclarecido (TCLE). As entrevistas foram gravadas com recurso de um aparelho MP4®, para garantir a autenticidade dos depoimentos representados pelas falas dos entrevistados para consecutivamente serem transcritas na íntegra. Como forma de garantir a segurança aos entrevistados, a ética que rege a pesquisa sobre o sigilo e o anonimato, foi utilizado o pseudônimo DOC (de docente) em caixa alta, seguido da numeração de 01 a 12, a qual foi determinada a partir da ordem de realização das entrevistas, de modo que todos os sujeitos da pesquisa puderam certificar-se de que suas identidades permaneceriam anônimas. Para análise dos discursos dos participantes foi utilizada a técnica de "Análise de Conteúdo" que, segundo Bardin (2016) é a organização sistemática dos dados coletados. Inicialmente os discursos foram transcritos, mantendo a originalidade das expressões dos entrevistados.

\section{RESULTADOS E DISCUSSÃO}

Participaram da pesquisa 12 enfermeiros docentes, dos quais $91,7 \%$ eram do gênero feminino, com predominância da faixa etária acima de 50 anos (41,7\%). 100\% da amostra possuía mestrado como pósgraduação stricto sensu, 91,7\% detinham o título de doutor e 33,3\% concluíram o pós-doutorado no currículo, 
$25 \%$ da amostra atuava como docente do ensino superior há mais de 30 anos, $16,7 \%$, mais de 20 anos, $50 \%$, mais de 10 anos e $8,3 \%$, menos de uma década. Dos professores entrevistados, além de ministrarem aula na graduação, $66,6 \%$ eram docentes no curso de especialização, $58,3 \%$, no mestrado e $50 \%$, no doutorado. $100 \%$ dos entrevistados apresentavam regime de trabalho por dedicação exclusiva com 40 horas semanais. 91,7\% dos docentes afirmaram já ter participado de algum curso que envolvesse a formação docente.

Os princípios fundamentais para que o enfermeiro exerça a docência com competência relacionam-se com o reconhecimento e a superação de obstáculos didáticos que afetam negativamente o processo de ensinoaprendizagem, não se limitando apenas ao espaço físico da sala de aula (RODRIGUES e SOBRINHO, 2008).

A adoção de estratégias de enfrentamento a dificuldades encontradas no processo de aprendizagem é de fundamental importância. O êxito da estratégia adotada dependerá muito de fatores inerentes tanto ao docente quanto ao aluno, fatores esses que dependem de motivação, conhecimento e principalmente persistência (MOURA e MESQUITA, 2010).

Aqui são apresentadas as estratégias usuais de enfermeiros docentes para melhoria das práticas pedagógicas. Ações como manter-se atualizado, participação em cursos e eventos científicos para aperfeiçoamento e qualificação, leitura rotineira, diagnóstico do feedback dos alunos acerca das aulas e conteúdos ministrados e produção científica foram alguns pontos discutidos com os entrevistados.

O docente, esclarecido de seus limites, põe-se em constante movimento, na procura por novos aprendizados que enriqueçam suas ações, saberes e relações pedagógicas na vivência com os alunos e que os ajudem a superar os obstáculos impetrados por cada nova turma de estudantes (ROSSATO et al., 2018). Quando questionados sobre o que fazem para melhorar suas práticas pedagógicas, os enfermeiros docentes demonstraram contínua busca de atualização, seja por meio da leitura e participação em cursos e eventos científicos que os qualifiquem e aperfeiçoem, como exemplificado nas faltas dos DOCs $01,02,03,05,09,10$, 11 e 12.

"Se eu vou dar uma aula essa semana, seja de que for, uma aula que eu já tô caduca de fazer, de ministrar, de estar com os alunos, eu vou, volto nas bases de dados onde tem... onde eu posso encontrar o que há de mais novo, o que há de melhor em relação aquilo pra não fazer aquela aulinha trivial ou então pra não ser uma aula que já esteja ultrapassada, entendeu?" - DOC 01

"Ah, meu filho, eu faço muitos cursos... Eu participo de muitos cursos, digamos, quando aqui tem sempre as oficinas pedagógicas no início de cada período, então eu participo efetivamente dessas oficinas... É... procuro cada vez mais melhorar... É... o nosso conteúdo, atualizar, verificar o que $o$ aluno mais necessita..." - DOC 02

"Além de participar de eventos científicos, ler... Ler sobre materiais das aulas, os assuntos das disciplinas e sobre a Enfermagem como um todo e também... é... atualizar o material das aulas que você faz todo semestre." - DOC 03

"Olha, eu estudo muito... Todo semestre a gente replaneja... Vê bibliografia nova..." - DOC 05

"É ler muito, além do conhecimento tá bem atualizado, referências atuais..." - DOC 09

"Eu leio muito, leio muitos artigos, vou pra congressos me atualizar, porque eu preciso, é minha obrigação. Eu sou consultora do Ministério da Saúde, então tô sempre olhando o que está saindo... Olho pro meu aluno, pro serviço, pra realidade do Brasil..." - DOC 10

"Eu leio... A única coisa que eu posso fazer, porque como eu sou dedicação exclusiva da UFPI eu dou aula também no Mestrado e no Doutorado, acabei de voltar de um pós-doutorado, então a minha facilidade... Eu fiz um curso de leitura dinâmica, eu tenho muita facilidade de ler, ler algo rápido e sintetizar aquilo." - DOC 11

"Olha, como eu te falei... Eu fiz esse curso, é um curso de especialização, 'Ativadores do processo de mudanças na formação dos profissionais da saúde', exatamente isso, buscando novas 
metodologias, metodologias ativas, inovadoras para se ensinar [...]. Eu acho que você tem que que estar se atualizando, tá lendo artigos, livros, coisas boas, coisas novas, né?" - DOC 12

Percebeu-se que a busca por atualização não se restringe somente ao momento da formação inicial, ela acompanha todo o trajeto profissional do docente, mediante uma relação dialética, como argumentada por Freire (2014) como essencial na prática pedagógica, quando coloca que "Quem ensina aprende ao ensinar e quem aprende ensina ao aprender".

Neste sentido, é essencial que o docente compreenda a real importância de manter-se atualizado, renovando a cada momento conhecimentos pedagógicos, éticos, tecnológicos, políticos e de conteúdo. Apenas com constantes atualizações, o professor conseguirá despertar 0 interesse dos alunos para 0 conteúdo e/ou disciplina que ele ministra.

Quase 92\% dos entrevistados afirmaram já ter participado de algum curso que envolvesse a formação docente. Nessa perspectiva, Maissiat e Carreno (2010) assinalam a importância do estímulo por parte das instituições de ensino superior à formação continuada desses professores, ocasionando, assim, o desenvolvimento de competências e habilidades pedagógicas necessárias ao saber, ao saber-ser e ao saberfazer, proporcionando autoavaliação, conduzindo para melhores ações pedagógicas.

Outro aspecto discutido e declarado pelos enfermeiros docentes foi como os alunos avaliam os docentes, os conteúdos e as disciplinas ministradas. Os relatos dos DOCs 06, 07, 08 e 09 revelaram a importância desse feedback.

"Essas atividades que a gente tenta sempre buscar com o aluno mesmo... O que está errado? O que eles estão achando daquele tipo de atividade? Está sendo bom o aproveitamento, se eles acham que poderia ser de outra forma... Então, a gente imediatamente modifica, pensa em outras formas, vai adaptando, eu acho que isso é a contribuição maior." - DOC 6

"Eu percebo, vou verificando a necessidade de aprendizado deste aluno, com isso eu vou incrementando e suplementando a aprendizagem dele, buscando prática, técnicas, induzindo o aluno para que ele busque o conhecimento individual, fora da sala de aula, e assim traga suas dúvidas e o aprendizado seja mais proveitoso." - DOC 07

"Estudar, buscar... Por existem situações em que você faz todo o planejamento pra uma aula, e você chega na aula e vê que o aluno não tinha conhecimento prévio que era necessário, aí você vê que aquela metodologia que você pensou que funcionou muito bem pra turma passada de repente não tá funcionando pra essa turma, então eu tenho que buscar, pensar "Não, como é que eu vou tentar? Como é que eu vou adaptar?' E assim, a gente tá sempre aprendendo..." - DOC 8

"[...] Ver o feedback do aluno, porque se eu dei uma aula hoje e eu senti que o aluno achou chata, então o que a gente pode fazer? A gente tem que trazer esse aluno pra dentro da sala de aula, até porque a gente tá na Enfermagem, que é um curso extremamente prático, que lida constantemente com o ser humano, que vai estar cuidando de vidas." - DOC 9

A prática do feedback no ensino é um meio eficaz usado na vivência acadêmica e docente para obtenção de melhor desempenho, importante na educação superior (FARIAS et al., 2015). Para Cardoso (2018), tal feedback deve ser mútuo, aluno-professor e professor-aluno. Esses retornos tornam o docente mais próximo, norteia, estimula e auxilia os alunos durante a realização de atividades, permite que aluno entenda seu desempenho, serve como fonte de troca de experiências e ajuda na formação do aluno autônomo.

Boccia e Souza (2014) destacam ainda a atenção que deve ser dada ao diálogo entre educador e discente, como forma de se obter feedback do aluno. Em sua obra "Pedagogia da Autonomia", Freire (2014) já afirmava "Não há docência sem discência". Faz-se necessário que haja um modo de compartilhamento de ideias e conhecimentos, e que esse compartilhamento seja bidirecional, para que assim se consiga estabelecer a 
troca de experiências, a construção de novos saberes e o recebimento pelo professor dos feedbacks positivos e negativos acerca dos conteúdos ministrados e de sua disciplina como um todo. É importante que haja respeito aos conhecimentos do educando, estímulo a criticidade, disponibilidade ao diálogo, consideração pela autonomia do aluno e necessidade do saber escutar.

A produção científica também foi pontuada quando questionados sobre maneiras de melhorar a prática pedagógica, como bem explana o DOC 4.

"Procurar escrever, mas escrever artigos que tragam uma coisa útil, prática pros docentes, pros nossos pares, pra comunidade." - DOC 04

Soares et al. (2013) consideram que a atitude de pesquisar deve ser incorporada como forma suplementar na práxis docente. A vivência na pesquisa é que faz com que o educador tenha a oportunidade de aprender mais para levar novos conhecimentos e/ou conhecimentos atualizados para sala de aula. Os autores destacam ainda a necessidade de os cursos da modalidade stricto sensu empenharem maior dedicação àqueles pesquisadores que ainda se encontram como alunos, mas que objetivam assumir a sala de aula. Para eles, o foco dos cursos stricto sensu não deve voltar-se somente à produção científica de conhecimento, mas sim atrelar esse conhecimento à prática ao qual o pesquisador (e futuro professor) e seus semelhantes estão inseridos.

\section{CONCLUSÃO}

Os discursos presentes neste estudo retrataram as estratégias utilizadas por enfermeiros docentes para melhoria de suas práticas pedagógicas. O professor, ao se deparar com fragilidades durante a formação do enfermeiro, diagnostica problemas sejam esses com suas aulas ou sua didática para determinada disciplina, seja com déficits prévios de alunos; planeja intervenções com o objetivo de reparar tais debilidades; implementa ações na busca de melhorias com base em resultados a serem alcançados; e realiza avaliações contínuas a fim de verificar recuperação do problema identificado na primeira etapa descrita.

O docente deve possuir certas habilidades que façam com que este consiga identificar precocemente qualquer sinal de limitação do aluno no processo de aprendizagem. Daí a relevância de ações como escuta ativa, eliminação de dúvidas, encorajamento, incentivo ao raciocínio crítico e empatia, pois o professor deve se atentar que, antes de ser educador, ele também já esteve ocupando a mesma carteira que seus alunos se encontram atualmente.

\section{AGRADECIMENTOS}

Os autores são gratos ao Departamento de Enfermagem da Universidade Federal do Piauí por autorizar a realização da pesquisa na referida instituição. Os autores agradecem ainda a todos aqueles enfermeiros docentes que deram suas contribuições, aceitando participar voluntariamente deste estudo.

\section{REFERÊNCIAS}

1. BARBOSA AC, AGUIAR GP. Percepções sobre a prática pedagógica docente do enfermeiro no ensino superior. Revista Univar, 2016; 2(16): 63-67.

2. BARDIN L. Análise de conteúdo. $1^{\mathrm{a}}$ ed, Edições 70, Brasil, 2016.

3. BOCCIA MB, SOUZA ACL. Prática docente: quatro pontos para reflexão. Revista Acadêmica Eletrônica Sumaré, $2014 ; 12(4): 1-11$.

4. CARDOSO ACS. O feedback aluno-aluno em um ambiente virtual de aprendizagem. Trabalhos em Linguística Aplicada, 2018; 57(1): 383-409. 
5. FARIAS CML. Feedback no processo de aprendizagem: percepção dos estudantes de Odontologia em uma universidade brasileira. Revista da ABENO, 2015; 15(3): 35-42.

6. FONSECA JPS, FERNANDES CH. O enfermeiro docente no ensino superior: atuação e formação profissional. Revista Série-Estudos, 2017; 22(45): 43-58.

7. FREIRE, P. Pedagogia da autonomia: saberes necessários à prática educativa. $53^{\mathrm{a}}$ ed. São Paulo: Paz e Terra, 2014.

8. GATTO JUNIOR JR, ALMEIDA EJ, BUENO SM. V. Docência no ensino superior: uma revisão sobre as tendências pedagógicas que permeiam o cotidiano do enfermeiro docente. Arquivos de Ciências da Saúde da UNIPAR, 2015; 19(2): 125-138.

9. JUNGES KS, BEHRENS MA. Prática docente no Ensino Superior: a formação pedagógica como mobilizadora de mudança. Revista PERSPECTIVA, 2015; 33(1): 285-317.

10. MAISSIAT GS, CARRENO I. Enfermeiros docentes do ensino técnico em enfermagem: uma revisão integrativa. Revista Destaques Acadêmicos, 2010; 3(2): 69-79.

11. MATTOS M, MONTEIRO FMA. A pesquisa narrativa na educação superior: inserção profissional de enfermeiros na docência. In: $3^{\circ}$ Congresso Ibero-Americano em Investigação Qualitativa, 2014; 2: 208-212.

12. MINAYO MCS. O desafio do conhecimento: Pesquisa qualitativa em saúde. 14a ed. São Paulo: Hucitec, 2014.

13. MOURA ECC, MESQUITA LFC. Estratégias de ensino-aprendizagem na percepção de graduandos de enfermagem. Revista Brasileira de Enfermagem, 2010; 63(5): 793-798.

14. RODRIGUES MTP, SOBRINHO JACM. Obstáculos didáticos no cotidiano da prática pedagógica do enfermeiro professor. Revista Brasileira de Enfermagem, 2008; 61(4): 435-440.

15. ROSSATO M, MATOS JF, PAULA RM. A subjetividade do professor e sua expressão nas ações e relações pedagógicas. Educação em Revista, 2018; 34(e169376): 1-20.

16. SANTOS CCM, PUGGINA ACG, PEREIRA LL. Fatores que influenciam a percepção de professores de enfermagem das competências na docência. Revista Família, Ciclos de Vida e Saúde no Contexto Social, 2016; 4(2): 86-97.

17. SOARES BIB, ARAÚJO R, LIRA, LM et al. Desvalorização da docência em detrimento da pesquisa universitária. In: XI Congresso Nacional de Educação (EDUCERE), Pontifícia Universidade Católica do Paraná, 13.23813.246, Curitiba: Editora Champagnat, 2013. 